\title{
SpaceLiner Cabin Escape System Design and Simulation of Emergency Separation from its Winged Stage
}

\author{
Stappert, S. ${ }^{1 *}$, Sippel, M. ${ }^{1}$, Bussler, L. ${ }^{1}$, Wilken, J. ${ }^{1}$, Krummen, S. ${ }^{1}$ \\ ${ }^{1}$ Space Launcher Systems Analysis (SART), German Aerospace Center (DLR), Institute of Space Systems, Robert- \\ Hooke-Straße 7, 28359 Bremen, Germany
}

The SpaceLiner is a visionary concept of a hypersonic passenger transportation system with two parallel winged stages based on rocket propulsion. This fully reusable system has been studied by the German Aerospace Center (DLR) for over a decade and has entered its project phase $A$ in 2017. Since it is supposed to transport up to 50 passengers on suborbital trajectories, high standards for safety and reliability have to be applied to this system. Hence, an emergency capsule (SpaceLiner Capsule) accommodating the passengers is foreseen that shall safely eject from the SpaceLiner passenger stage in case of a critical emergency. This paper focuses on the separation process and investigates the baseline capsule ejection procedure such as the cabin and separation motor design. Furthermore, the status and recent developments of the SpaceLiner are presented.

\section{Nomenclature}

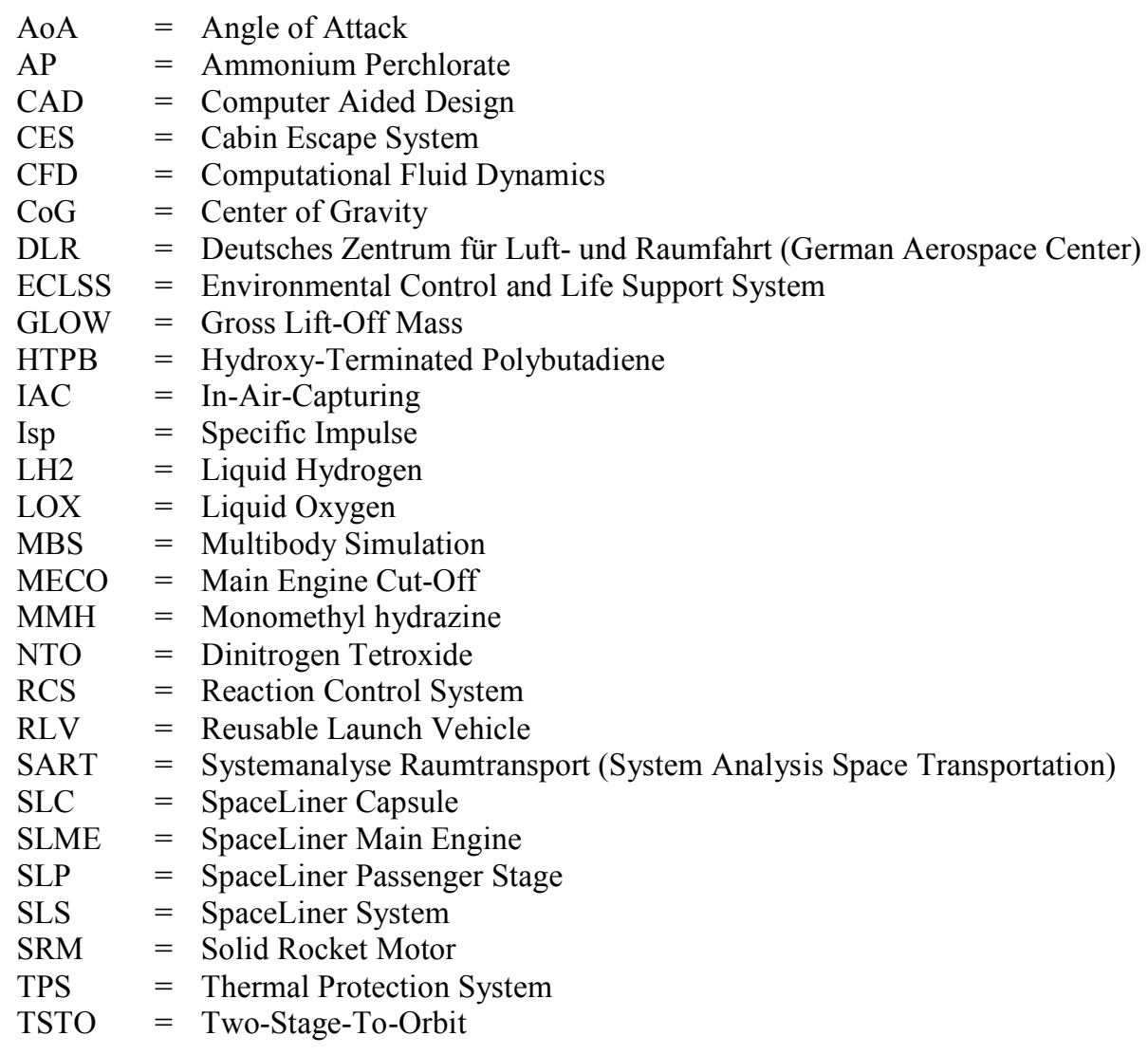

\footnotetext{
* Scientific Employee, Space Launcher System Analysis (SART), German Aerospace Center (DLR), Young Professional Member
} 
TVC $=$ Thrust Vector Control

\section{Introduction}

The SpaceLiner is a concept of a hypersonic suborbital launch vehicle which is capable of transporting 50 passengers over ultra-long-haul distances (e.g. Europe to Australia in 90 minutes). It has been under investigation at DLR since 2005 [1] - [7]. The current baseline, also known as SpaceLiner 7-3, is shown in Fig. 1. The vehicle consists of two parallel mated stages: The SpaceLiner Passenger stage (SLP) and the SpaceLiner Booster (SLB). Both stages are propelled by in total 11 LOX/LH2 SpaceLiner Main Engines (SLME) [3], of which 2 engines are mounted to the SLP and the remaining 9 engines are mounted to the SLB (see Fig. 2). The SLP also accommodates the SpaceLiner Capsule (SLC) where the passengers and the crew are seated during flight. The SLC further contains the ECLSS system to provide a safe environment for the passengers.

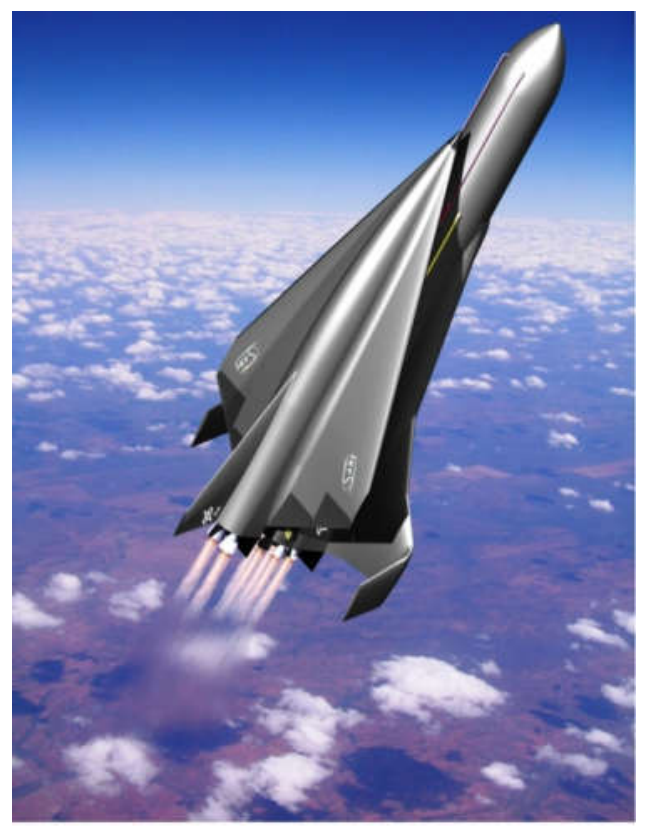

Fig. 1: The SpaceLiner vision of a rocket-propelled intercontinental passenger transport is one of the most challenging projects in hypersonic research

In a nominal mission, the SpaceLiner takes off vertically with all engines running at full thrust. The stages are equipped with a propellant crossfeed system which feeds propellant from the SLB to the SLP during ascent until stage separation at a velocity of around $3.5 \mathrm{~km} / \mathrm{s}$. The SLB then performs an atmospheric re-entry and shall be captured and towed back to its launch site by a conventional airplane (In-Air-Capturing). The SLP continues to accelerate up to an altitude of around $80 \mathrm{~km}$. After MECO the SLP performs a continuous gliding re-entry flight to its destination where it lands horizontally on an airstrip [1] - [7]. 


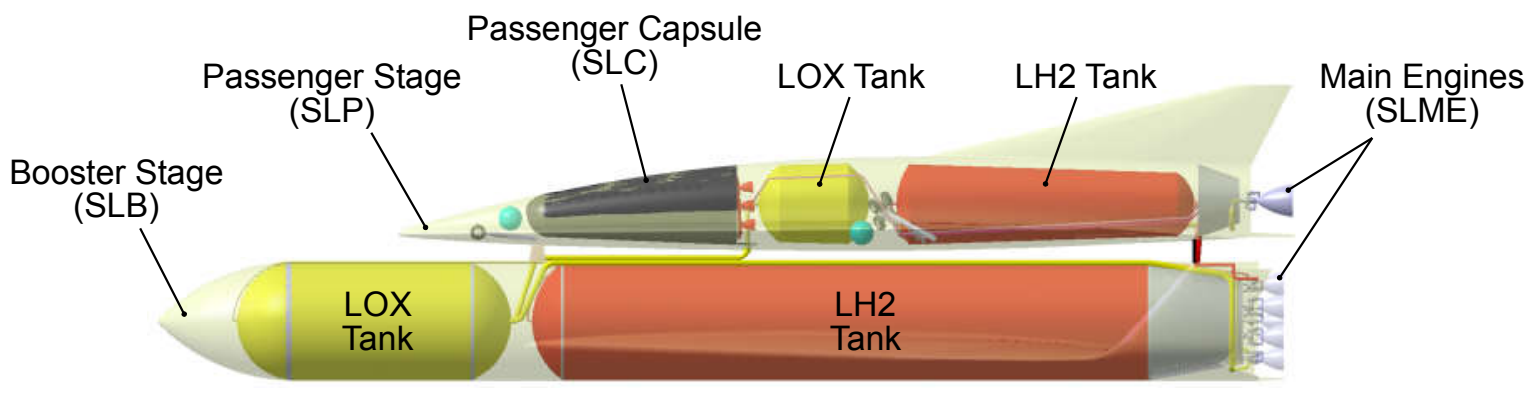

Fig. 2: Configuration of the current SpaceLiner 7-3 design

The SpaceLiner has to offer a higher standard of safety compared to conventional rocket-propelled launch vehicles since it is to be operated with a high launch rate and a high number of reuses. Hence, the SLC has to feature a cabin escape system which, in case of a life-threatening emergency, safely ejects the passengers and guards the capsule to a designated landing site. Military aircraft with ejectable cockpit parts (e.g. F111) have already successfully been built and used. The Hermes spacecraft which was studied in Europe between 1985 and 1992 was foreseen to be equipped with a suspended crew capsule that could be ejected in the case of an emergency. Also, first studies on a second generation Space Shuttle considered a detachable crew compartment for emergency situations (see Fig. 3).

However, the design of such a cabin and its ejection system for a hypersonic passenger transport system is a highly complex and demanding task since no ejectable passenger cabin of this size was ever built. The design process is highly interdependent and iterative and the herein presented design solutions are subject to ongoing study and iterations.

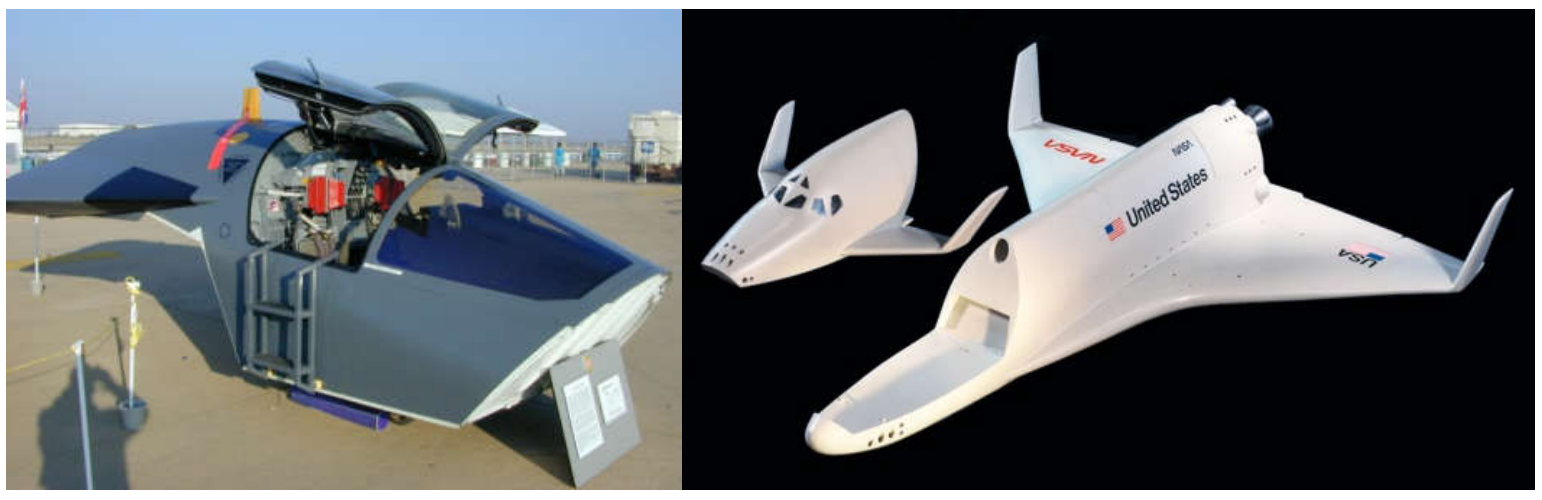

Fig. 3: F111 ejectable cabin part (left) and JSC Shuttle IIc with detachable crew compartment

The design of the capsule and said cabin escape system were subject to several studies within the DLR and the framework of the HYPMOCES study [8] - [12]. A safe ejection procedure at every demanded flight point has to be successfully demonstrated to qualify the cabin escape system. However, the separation process itself was never simulated in detail considering ignition timing of the separation motors, possible jettisoning of SLP fuselage parts, influence of aerodynamics and fulfilment of the mission requirements posed upon the capsule (see section IV.A). Hence, a simulation framework of the emergency separation process was set up to simulate the ejection process of the baseline SLC (see section IV.B). The simulation was conducted using the multibody dynamic simulation tool SIMPACK. This tool offers the possibility to simulate the kinematics and kinetics of the separation process. In this paper, the zero-zero ejection with zero initial velocity and altitude at the launch pad without collision detection is presented. Furthermore, the current status of the SpaceLiner Capsule and its separation motors is described. 


\section{SpaceLiner 7 Architecture and Geometry}

The current arrangement of the two vehicles at lift-off is presented in Fig. 2. Stage attachments are following a classical tripod design. The axial thrust of the booster is introduced through the forward attachment from the booster intertank into the nose gear connection structure of the orbiter. The aft attachment takes all side and maneuvering loads. The option of a belly to belly connection is not preferred for two reasons: A strong unintended aerodynamic interaction of the two wings and propellant crossfeed lines on the booster which would be directly affected by hypersonic flow during reentry of this stage. All LOX-feedlines and the LH2-crossfeed connection are attached on the booster's top outer side and are thus subjected to flow in the relatively cold wake region. The feedlines of the upper stage are completely internal and ducted underneath the TPS.

The current baseline design of the SLC is also shown in Fig. 2. The SLC is positioned in the SLP between the LOX tank (colored in yellow) and the water tank which stores water for the actively cooled TPS (colored in blue). The SLC is suspended non-integrally in the SLP structure, so it can be removed from the SLP structure before launch and after landing to allow a comfortable exit of the passengers. A part of the upper body structure of the SLP is cut out to allow for accommodation of the capsule.

The main dimensions of the 7-3 booster configuration are listed in Table 1 while major geometry data of the SpaceLiner 7-3 passenger stage are summarized in Table 2.

Table 1: Geometrical data of SpaceLiner 7-3 booster stage

\begin{tabular}{ccccccc}
\hline \hline $\begin{array}{c}\text { Length } \\
{[\mathrm{m}]}\end{array}$ & $\begin{array}{c}\text { Span } \\
{[\mathrm{m}]}\end{array}$ & $\begin{array}{c}\text { Height } \\
{[\mathrm{m}]}\end{array}$ & $\begin{array}{c}\text { Fuselage } \\
\text { diameter } \\
{[\mathrm{m}]}\end{array}$ & $\begin{array}{c}\text { Wing leading } \\
\text { edge angles } \\
{[\mathrm{deg}]}\end{array}$ & $\begin{array}{c}\text { Wing pitch } \\
\text { angle } \\
{[\mathrm{deg}]}\end{array}$ & $\begin{array}{c}\text { Wing dihedral } \\
\text { angle } \\
{[\mathrm{deg}]}\end{array}$ \\
\hline 82.3 & 36.0 & 8.7 & 8.6 & $82 / 61 / 43$ & 3.5 & 0 \\
\hline \hline
\end{tabular}

Table 2: Geometrical data of SpaceLiner 7-3 passenger stage

\begin{tabular}{ccccccc}
\hline \hline $\begin{array}{c}\text { Length } \\
{[\mathrm{m}]}\end{array}$ & $\begin{array}{c}\text { Span } \\
{[\mathrm{m}]}\end{array}$ & $\begin{array}{c}\text { Height } \\
{[\mathrm{m}]}\end{array}$ & $\begin{array}{c}\text { Fuselage } \\
\text { diameter } \\
{[\mathrm{m}]}\end{array}$ & $\begin{array}{c}\text { Wing leading } \\
\text { edge angles } \\
{[\mathrm{deg}]}\end{array}$ & $\begin{array}{c}\text { Wing pitch } \\
\text { angle } \\
{[\mathrm{deg}]}\end{array}$ & $\begin{array}{c}\text { Wing dihedral } \\
\text { angle } \\
{[\mathrm{deg}]}\end{array}$ \\
\hline 65.5 & 33.0 & 12.1 & 6.4 & 70 & 0.4 & 2.65 \\
\hline \hline
\end{tabular}

\section{SpaceLiner Cabin and Rescue System}

In this section, the mission requirements directly affecting the SLC and cabin escape system design are presented. Furthermore, the capsule baseline design including the solid rocket separation engines is described and alternative concepts considered for the design are presented.

\section{A. Separation Requirements}

The SpaceLiner mission requirements document dictates several requirements that have to be met by the cabin escape system [13]. The specific requirements considering maximum load factor or safety distance in case of a detonation were derived from NASA or aircraft design guidelines and are valid for every point of the mission [14], [15]:

- PAX and staff risk of fatalities shall be less than $10^{-5}$ (TBC in phase A); third party risk of fatality shall be less than $10^{-7}$ (TBC in phase A)

- Boarding and de-boarding has to occur when the SLC is horizontal on the ground

- Quick and reliable integration of the SLC into the SLP before launch (vertical on launch pad) and quick and reliable separation after landing

- Autonomous flyback to earth after emergency separation

- Maximum allowed acceleration of $12 \mathrm{~g}_{0}$ in axial direction for 2 seconds and $3.5 \mathrm{~g}_{0}$ in lateral direction 
- Safe distance of $290 \mathrm{~m}$ has to be achieved in 2.9 seconds

- Ejection in all nominal flight conditions possible

- Ejection in a majority of off-nominal flight conditions possible

Fig. 4 shows several critical, nominal flight points along the SpaceLiner mission profile that will be used as design points for the capsule ejection system. These points include the launch pad abort (1), also known as zero-zero ejection with zero initial velocity and altitude, the point of maximum dynamic pressure during ascent (2), the point of booster separation (3), the point of SLP MECO (4) and the point of maximum heatflux during descent (5). Furthermore, the capsule ejection shall be possible and safe in off-nominal conditions. In this work, only the launchpad ejection, being the most demanding abort scenario considering safety distance and load limitation [17], has been investigated with the multibody analysis software. Since the off-nominal conditions are not defined in this phase of the study yet, they are not considered in the following analysis. However, in future work those off-nominal conditions shall be considered and the ejection procedure has to be evaluated at those points.

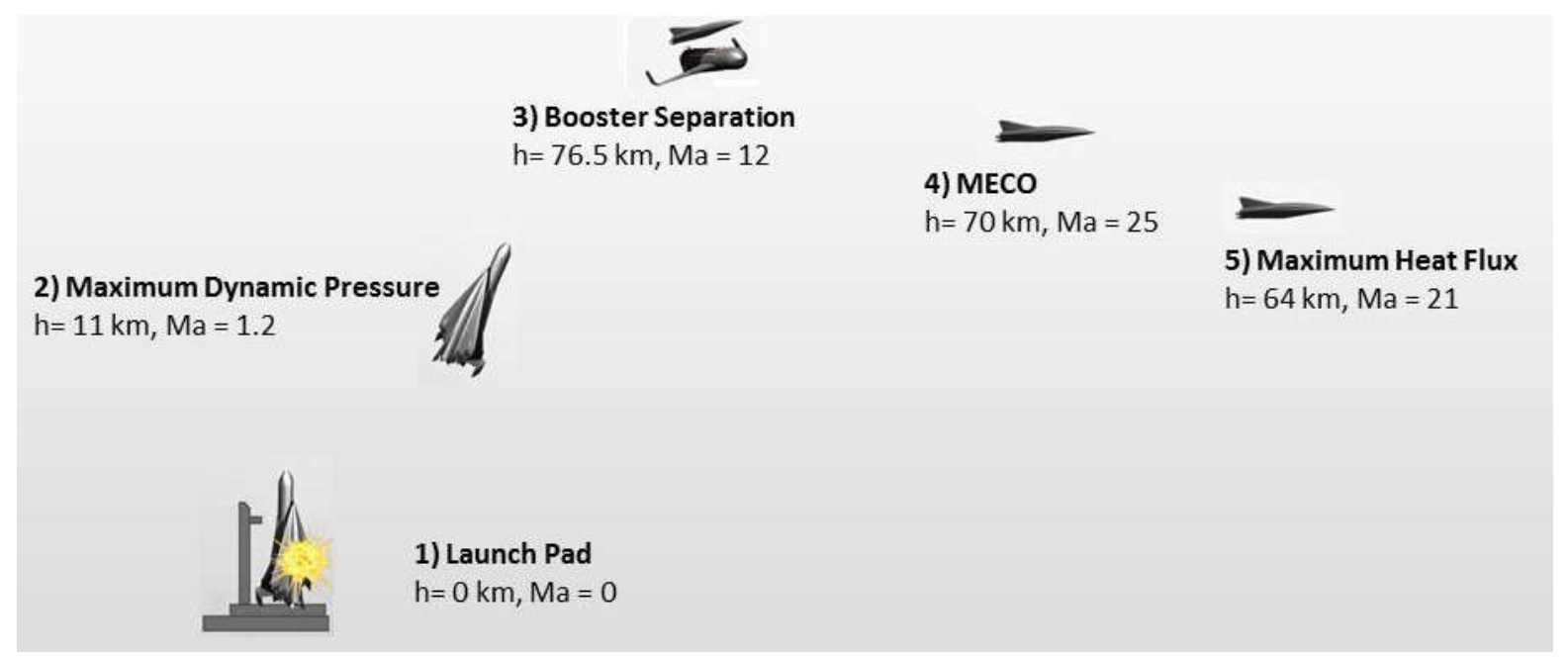

Fig. 4: Critical mission points for the design of the Capsule Ejection System

\section{B. Baseline Cabin Definition}

The passenger cabin of the SpaceLiner has two major functions: first, providing a comfortable pressurized travel compartment which allows for horizontal entrance of the passengers and secondly serving as a reliable rescue system in case of catastrophic, life-threatening events. Thus, the primary requirements of the cabin are the possibility of being firmly attached late in the launch preparation process and fast and safely separation in case of an emergency. Overall length of the current baseline of the capsule for 50 passengers (without separation motors) is $15.6 \mathrm{~m}$ and its maximum external height is $5.6 \mathrm{~m}$ (see Fig. 5). The capsule should be separated as easily and quickly as possible. Therefore, it currently is designed as a non-integral part of the fuselage structure, however, its upper section is conformal with the SpaceLiner's fuselage while the lower side is fully protected by the fuselage bottom structure.

The capsule should be able to fly autonomously back to Earth's surface in all separation cases. The abort trajectories are primarily influenced by the mass of the capsule and the aerodynamic performance with the most important subsystems being the separation motors, the thermal protection system (TPS), and the structure. These three subsystems have been investigated and sized for function, performance, and mass.

Four critical flight points have been chosen to simulate the abort trajectory in order to demonstrate that the SpaceLiner7 baseline capsule is able to fly safely back to Earth during any possible abort scenario [15]. The separation motors are designed to separate the capsule from the orbiter at most demanding launch-pad abort, without exceeding recommended maximum acceleration limits. The SRM must provide a high acceleration in a very short period of time. Due to severe geometry constraints, it has been decided to utilize a five motor configuration. Each motor has an approximate sea-level thrust of $750 \mathrm{kN}$ and a burn time of slightly above $2 \mathrm{~s}$. 


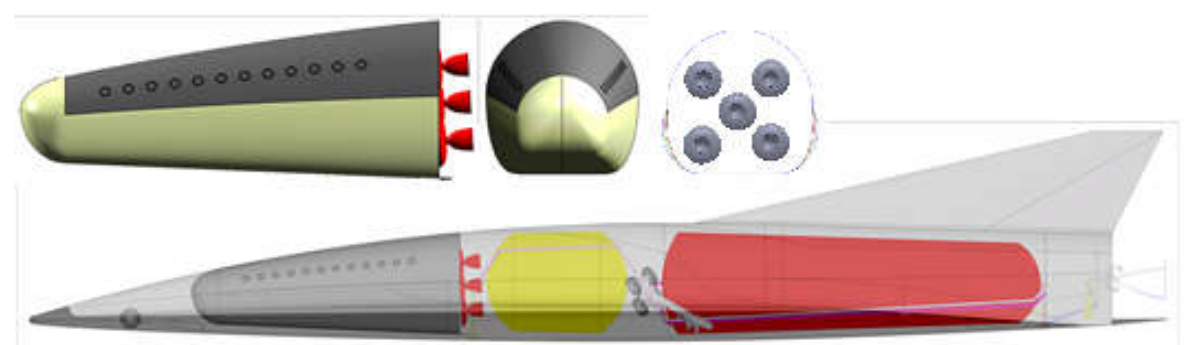

Fig. 5: SpaceLiner baseline rescue capsule (at top in side, fwd. and aft view) and integration into mothership version 7 (side view)

The capsule can be subdivided in a pressurized cabin of conical shape and an outer aerodynamic shell formed by the thermal protection system (TPS) which provides space for housing several non-pressurized subsystems [30]. The TPS of the SpaceLiner 7 capsule is required to withstand several different heat load conditions driven by the different nominal and abort cases it encounters. During nominal flight, the capsule is considered part of the passenger stage.

The current requirement of capsule separation being feasible at any flight condition and attitude is highly challenging from a technical point of view. The analysis of the separation process will be presented in section V. Alternative capsule integration concepts have been proposed and technically analyzed [12]. However, each of the explored design options is linked to severe challenges and drawbacks, including the baseline.

A preliminary separation process of the baseline SLC was already studied in [14] and is shown in Fig. 6. The capsule would first have to be accelerated axially (Frame 1) to enable the SLC to be tilted upwards without colliding with the SLP structure behind the capsule (Frame 2). Then, the solid rocket motors would be ignited (Frame 3), accelerating the SLC away from the SLP (Frame 4). This preliminary analysis showed that an ejection of the capsule is not possible without jettisoning parts of the SLP fuselage. Furthermore, the separation process would be complex, since an upward motion has to be induced before the ejection motors ignite. It has to be proven that the timing of the upward motion with the ignition of the solid motors can be achieved in a manner that guarantees safe and clean separation in every investigated flight point. Nevertheless, this ejection procedure was used as the baseline ejection procedure for the set-up of the simulation framework.
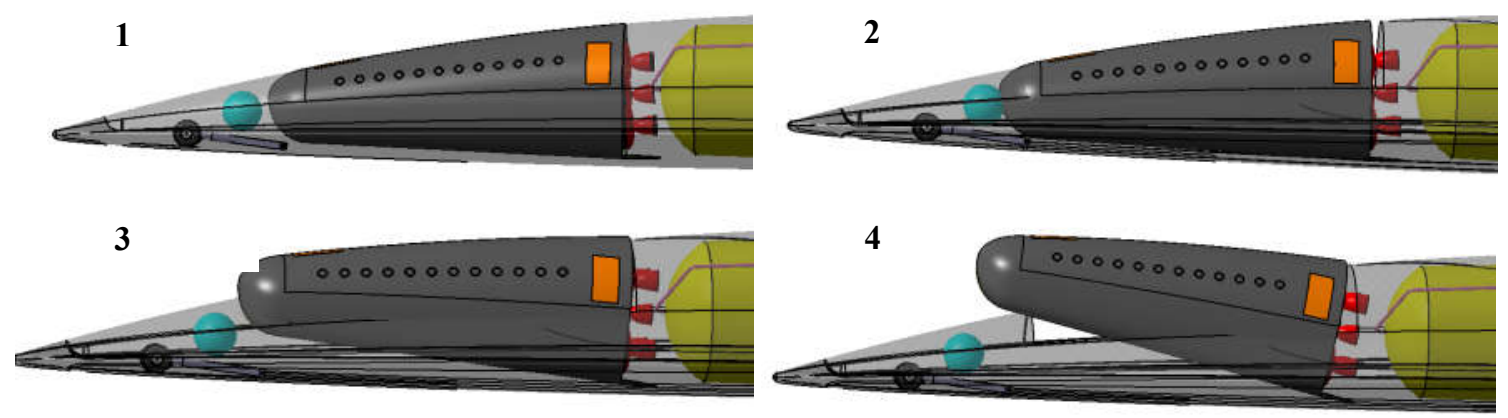

Fig. 6: Preliminary simulation of the separation process of the baseline SLC

\section{Separation Motors}

The separation motors attached to the rear end of the SpaceLiner Capsule are of crucial importance for the capsule ejection procedure, since they provide the thrust to accelerate the capsule away from the SLP and SLB. Hence, the design and possible solutions for this system have been studied in detail at DLR-SART [16], [17]. The current baseline (see Fig. 5) features 5 solid rocket motors that provide sufficient thrust at every design point to reach a safe distance without exceeding the limitations as specified in the requirements (see section IV.A). 
Table 3: Engine data for different separation engine design options

\begin{tabular}{lllll}
\hline Design Option & & $\begin{array}{l}\text { Solid single }- \\
\text { nozzle }\end{array}$ & $\begin{array}{l}\text { Solid multi- } \\
\text { nozzle }\end{array}$ & Liquid \\
\hline Number of Engines & {$[-]$} & 5 & 5 & 5 \\
Chamber pressure & {$[\mathrm{MPa}]$} & 15 & 15 & 6.9 \\
Expansion Ratio $\epsilon$ & {$[-]$} & 15 & 21.85 & 4 \\
Propellant & {$[-]$} & $\mathrm{Al} / \mathrm{AP} / \mathrm{HTPB}$ & $\mathrm{Al} / \mathrm{AP} / \mathrm{HTPB}$ & $\mathrm{MMH} / \mathrm{NTO}$ \\
Isp (sea-level) & {$[\mathrm{s}]$} & 268.1 & 265.3 & 267.6 \\
$\begin{array}{l}\text { Isp (vacuum) } \\
\text { Total Mass of } \\
\text { engines and tanks }\end{array}$ & {$[\mathrm{s}]$} & 284.7 & 290 & 278 \\
\hline
\end{tabular}

However, recent studies of these separation motors at DLR-SART considered different options for the separation motor design such as multi-nozzle solid motors and liquid propellant engines running on pressurized NTO and MMH [17]. Table 3 shows a comparison of the different design options considered for the SLC. It is important to note that the mass includes propellant and engine dry mass for the solid rocket motors and propellant, engine and tank mass for the liquid, pressure-fed engines. The masses were calculated using an ejection in vacuum as reference point. The mass comparison indicates that the multi-nozzle engine option might be viable option for the separation engine design. Hence, the cabin separation procedure will also be evaluated with multi-nozzle separation engines in future studies. The design criteria of the different engine options are discussed in the following paragraphs.

\section{Single-Nozzle Solid Rocket Motors (Current Baseline)}

The current baseline features 5 single-nozzle solid rocket motors using a mixture of $68 \%$ AP, $20 \%$ aluminum and $12 \%$ HTPB as propellant. The engines' design is restricted by the available space at the rear end of the capsule. Hence, the motors are quite short with a comparably large diameter (compare Fig. 7). The burn time of the motors is slightly above 2 seconds. The maximum thrust with a chamber pressure of $\mathrm{pc}=15 \mathrm{MPa}$ is around $856 \mathrm{kN}$ at sealevel (Isp = 268 s) and $908 \mathrm{kN}(\mathrm{Isp}=285 \mathrm{~s})$ in vacuum. The total mass of a single engine is approximately $693 \mathrm{~kg}$ leading to a total mass of all motors of 3.47 tons.

The advantage of a single-nozzle motor is the simple design. Furthermore, only one nozzle has to be produced and accommodated in the motor. Nevertheless, the expansion ratio of a single- nozzle motor is not optimal since the nozzle length is restricted by the space available between the capsule and the front LOX tank in the SLP (compare Fig. 5). In the current design, the exit pressure at the nozzle end is 1.5 bar which not optimal for neither a sea-level nor a vacuum ejection. Hence, multi-nozzle engines were considered since it allows an engine equipped with several small nozzles with a more optimal expansion ratio.
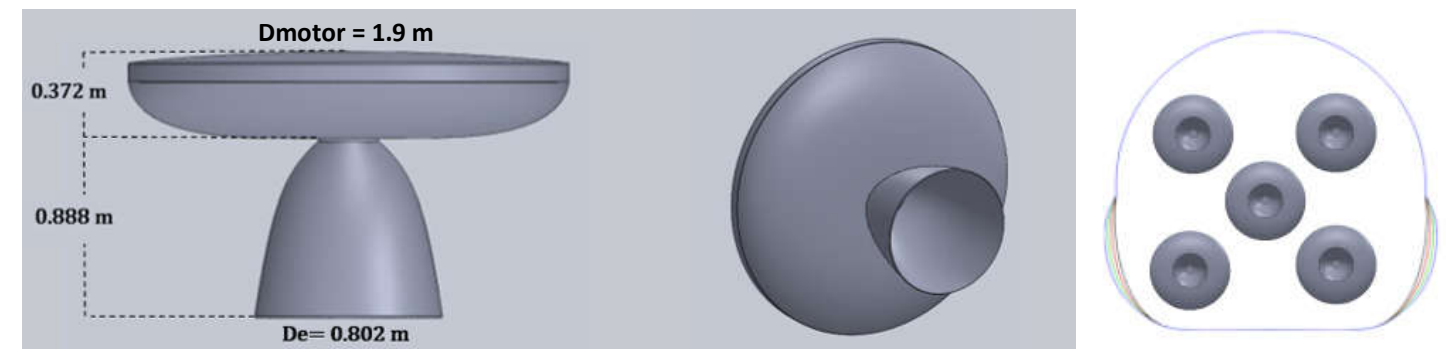

Fig. 7: Single-nozzle solid separation engines and accommodation at the rear end in the SLC

\section{Multi-nozzle Solid Rocket Motors}

The multi-nozzle engines are directly derived from the single-nozzle engines and are operated at the same chamber pressure $(\mathrm{pc}=15 \mathrm{MPa})$. The total diameter was kept at $1.9 \mathrm{~m}$. Due to the use of multiple nozzles, a lower exit pressure of $0.09 \mathrm{MPa}(0.9$ bar) could be reached for each nozzle, thus rendering the expansion ratio more optimal compared to the single-nozzle solution at vacuum conditions. The Isp in vacuum increase to about $290 \mathrm{~s}$, 
whereas the sea-level Isp decreases to $265.3 \mathrm{~s}$. The decrease in sea-level Isp could be critically considering that the launchpad abort case is until now the most demanding ejection point. This issue will be addressed in future work and the ejection procedure will be simulated using multi-nozzle engines.

The advantage of the multi-nozzle solution is the fact that the nozzles are shorter and the separation engines can be thus easily accommodated in the SLC. Additionally, the total mass can be reduced since propellant can be saved due to the higher vacuum Isp. However, the use of multiple nozzles increases the dry mass of the separation engines.
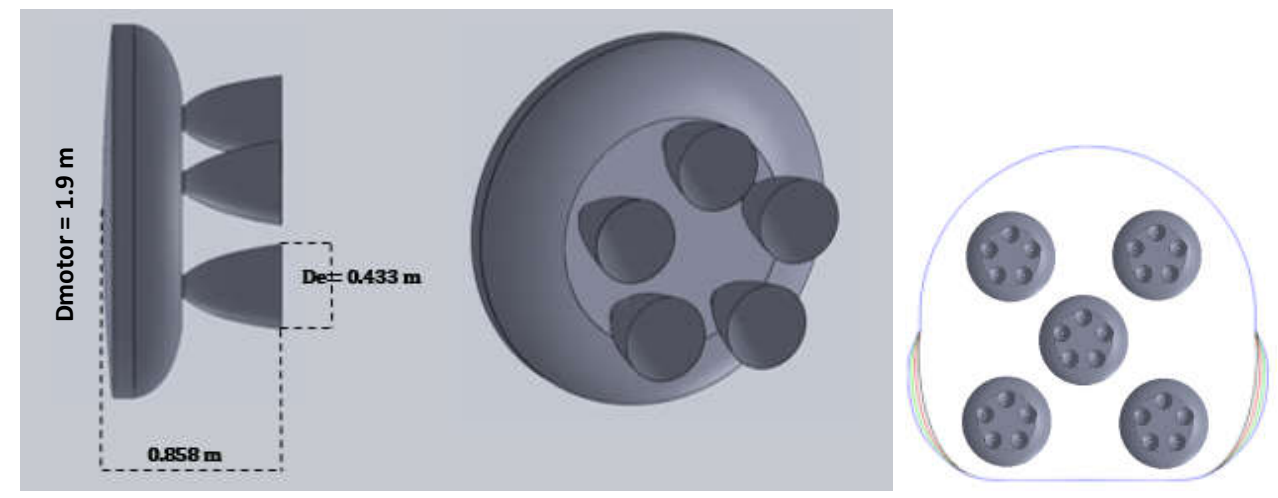

Fig. 8: Multi-nozzle solid separation engine with 5 nozzles and accommodation in the SLC

\section{Pressure-Fed Liquid Propellant Engines using $M M H / N T O$}

The third design option considered for the separation system is a pressure-fed, liquid propellant engine using $\mathrm{MMH}$ and NTO as propellants. The engines designed for the SLC are operated at a chamber pressure of pc = $6.9 \mathrm{MPa}$ and a mixture ratio of 1.96. A higher chamber pressure with pressure-fed engines is not favorable in reality, since the propellant tank size and mass increases significantly with higher tank pressure. The liquid propelled engines reach a vacuum Isp of $278 \mathrm{~s}$ and a sea-level Isp of $267.7 \mathrm{~s}$. This option offers the advantage of having engines that can be throttled according to the required separation profile. However, the installation of additional tanks, propellant feed hardware and pressure valves increases the complexity and the mass of the system. The required reliability of the system will also necessitate multiple redundancies within the entire liquid propulsion system.
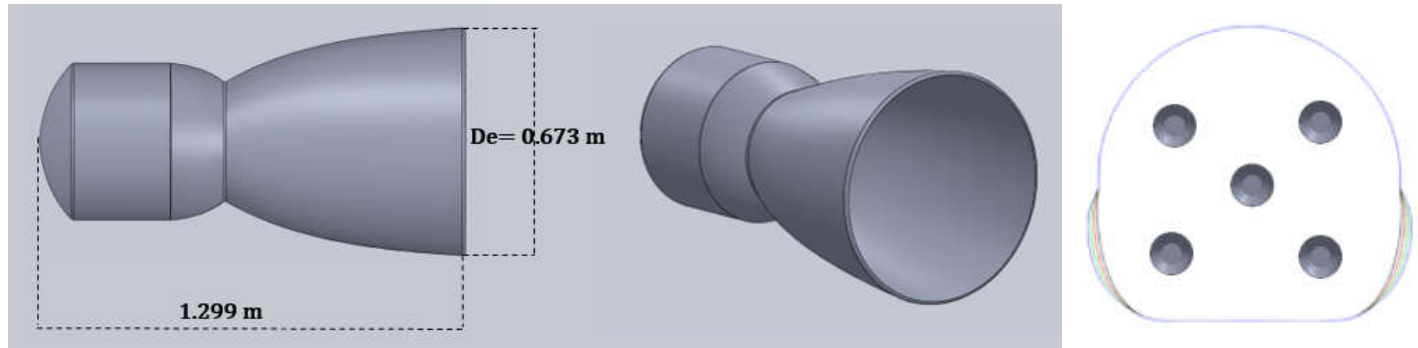

Fig. 9: Pressure-fed liquid propellant motors with MMH/NTO

\section{Alternative Concepts}

The SLC design is subject to optimization and different solutions are considered in this paper. The SLC design has to fulfil the requirements of accommodating the passengers and sustaining a pressurized, breathable environment while being easily separable and ejectable from the SLP. In the current project phase A an optimal design solution of the SLC shall be found that fulfils all necessary requirements. The design process of the SLC thus is highly iterative and interdisciplinary, since all design solutions have to be considered in the frame of a passenger capsule and lifesupport system as well as being subjected to detailed analysis of integration, separation, emergency ejection and overall system safety. The optimal solution will be a trade-off between all of these factors.

The baseline concept (named Concept A) and an alternative concept (Concept B) are presented in Fig. 10. The Concept B features the SLC being the complete nose section of the SLP. The SLC capsule would then accommodate all subsystems that are contained in the nose section of the SLP, such as the front landing gear and the water tank. 
Hence, the SLC mass and the system complexity would increase. However, the separation itself would be less complex compared to the concept A, since only acceleration in axial direction is necessary without having to induce an upward motion as for the SLC baseline. Nevertheless, releasable attachment points between the SLC and SLP or explosive devices severing the connecting structure have to be installed. The former imposes higher structure masses on the system, the latter might be less safe due to fragmentation.

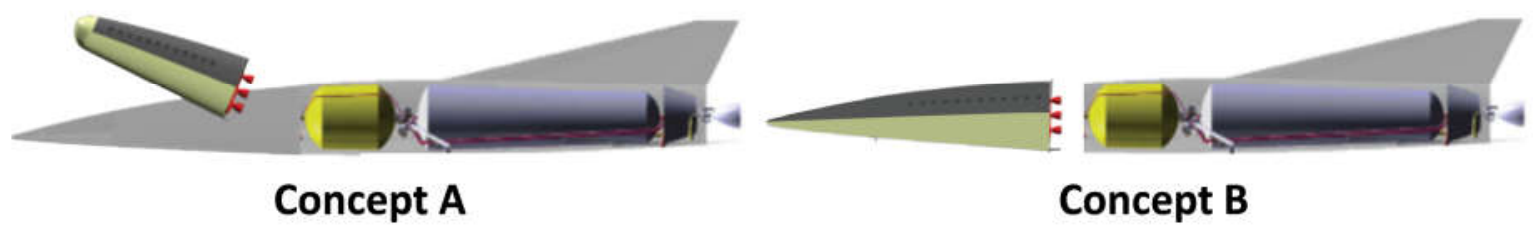

Fig. 10: Baseline Concept $A$ and alternative

Other alternative concepts of the SLC were studied at DLR but in less detail. Fig. 11 shows a concept were the upper nose section (marked in green) is the SLC. This approach resembles the Space Shuttle successor concept study depicted in Fig. 3 has the advantage of having less mass than the concept B and the separation procedure is less complex than the one from concept A.

As for today, only the Simpack model of the baseline concept has been set up (see section V). It is planned to simulate the separation process of the baseline capsule including collision dynamics next and to set up and simulate the models for the alternative concepts presented in this section.

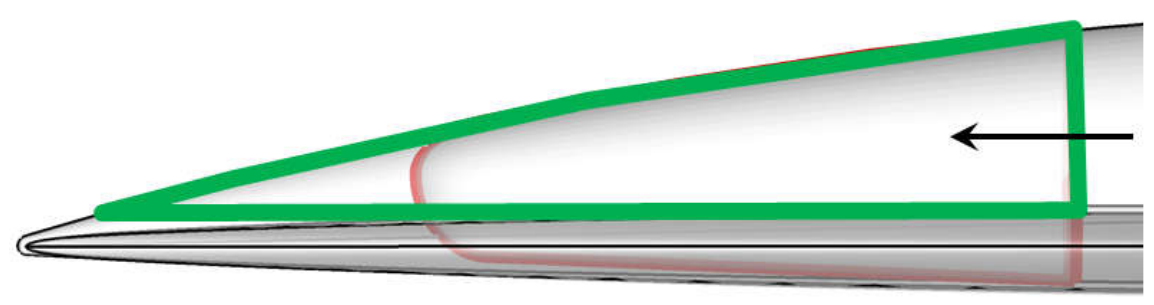

Fig. 11: Alternative concept of the cabin escape system

\section{SpaceLiner Capsule Ejection Simulation}

\section{A. Simpack Model}

The simulation of the separation process is conducted with the MBS program Simpack [19]. Fig. 12 shows the Simpack model of the SLP including the front water tank and the propellant LOX tank and the capsule including the separation motors. The geometrical model was taken from the respective SpaceLiner CAD model from CATIA. The simulation conducted until now is a 6-DOF simulation with no collision detection and modelling. Hence, the capsule follows a trajectory only being dictated by all forces and moments acting upon the capsule without considering any interaction with the passenger stage. This simplification allows to already identify problems or difficulties of the separation without setting up a complicated dynamic model.

The capsule is assumed to be connected to the SLP structure during flight. The positioning and kind of joint connection used to connect both components with each other shall be determined based on first simulation results and structural calculations in upcoming work. In this simulation, the velocity and altitude of the SpaceLiner are set to 0 , which means a so called "zero-zero" ejection (ejection at the launchpad with zero altitude and zero velocity) is simulated. The separation procedure starts with the separation of the joint connections and the ignition of the center engine to push the capsule forward. At the same time a force of $350 \mathrm{kN}$ for about 0.2 seconds is imposed on the nose of the capsule to push it upwards.

After, the nose tilt-up, the remaining engines are then ignited within 0.1 seconds after ignition of the center engine. The solid rocket motors burn for about 2 seconds and produce a maximum thrust of slightly more than 
$850 \mathrm{kN}$ (see Fig. 13). After burn-out of the engines the capsule follows a ballistic trajectory. Note that there are no aerodynamic forces implemented in this simulation. In further work, the aerodynamic forces and moments shall be simulated by coupling the Simpack calculation with a Simulink model of the aerodynamics. Additionally, CFD calculations in cooperation with ONERA shall be conducted to take flow interaction between the two stages and further effects into account, especially during hypersonic flight.

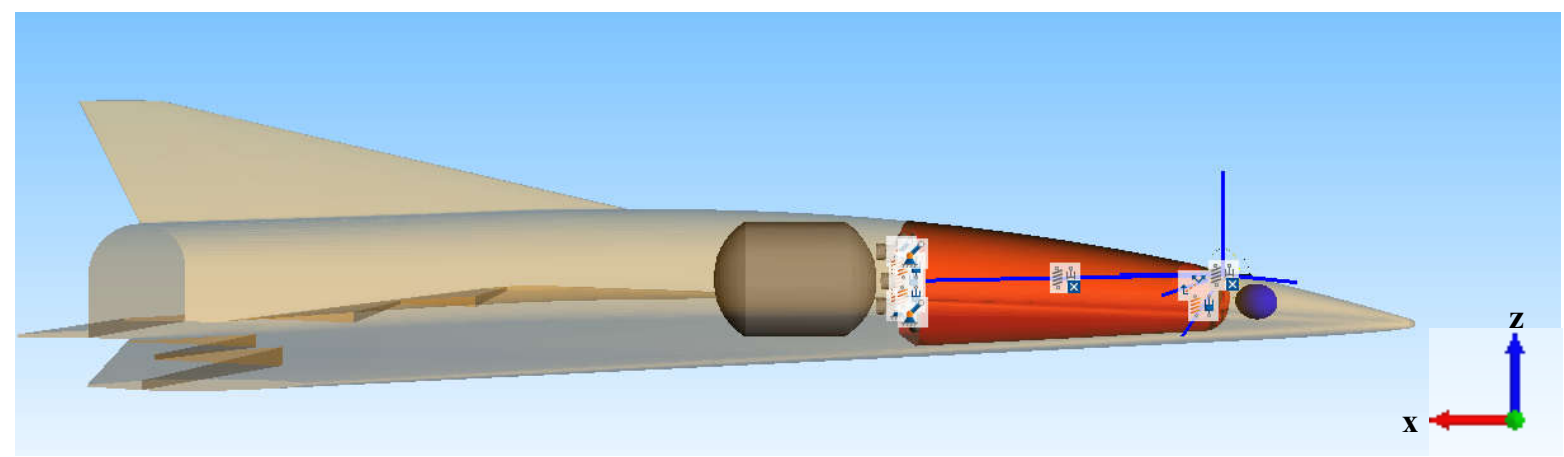

Fig. 12: Simpack Model of SLP and SLC including front water tank and LOX tank

It is important to note that this simulation is just a preliminary investigation of the capsule dynamics to determine if the safety requirements can be met. Until now, it is unclear where the solid rocket motor producing the force for the tilting of the capsule should be located and how high the necessary thrust and burn time would be. This also has to be investigated and determined in the near future by using the results of this first analysis. Since no collision interactions are modelled, this preliminary simulation is meant to point out the difficulties and major problems of the separation dynamics before going into more detail in the next step. However, a major problem of the baseline ejection procedure is the tilt-up of the nose prior to engines ignition since the timing has to be determined and a high force at the nose has to be produced to enable such high angular accelerations. Another problem that has to be taken into consideration is the fact that the angular rate at the end of the separation motor burns has to be counteracted by the RCS. Hence, the RCS system counter measurements should be included in future simulations to determine if the RCS is sized adequately.

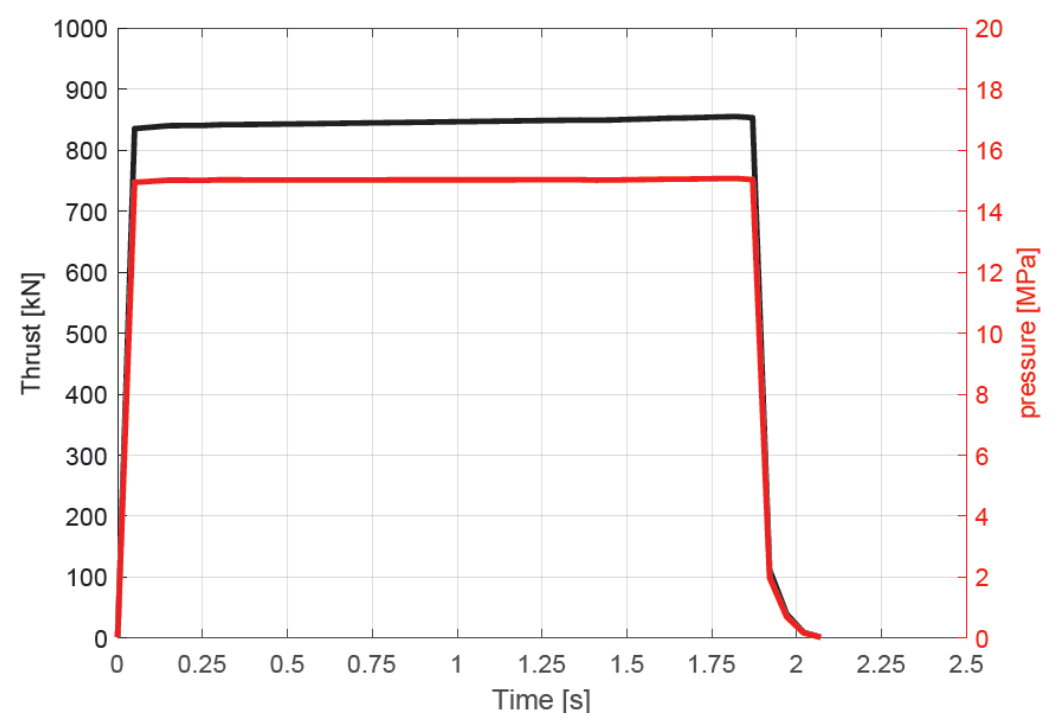

Fig. 13: Thrust Profile and chamber pressure of the solid motors at sea-level pressure

\section{B. Results of Baseline Launchpad Ejection}

The results of the preliminary simulation are shown in Fig. 14 to Fig. 16. Fig. 14 shows the position and accelerations of the SLC's CoG with respect to the inertial system. The accelerations are shown in SLC body-fixed coordinates with the coordinate system defined as shown in Fig. 12. The SLC reaches a distance of about $340 \mathrm{~m}$ 
within the 2.9 seconds specified in the requirements (see section IV.A), thus fulfilling the minimum required distance of $290 \mathrm{~m}$. The absolute acceleration of the SLC is about $11 \mathrm{~g}$ with almost all acceleration occurring along the $\mathrm{x}$-axis except for the first 0.2 seconds during the tilt-up of the nose.
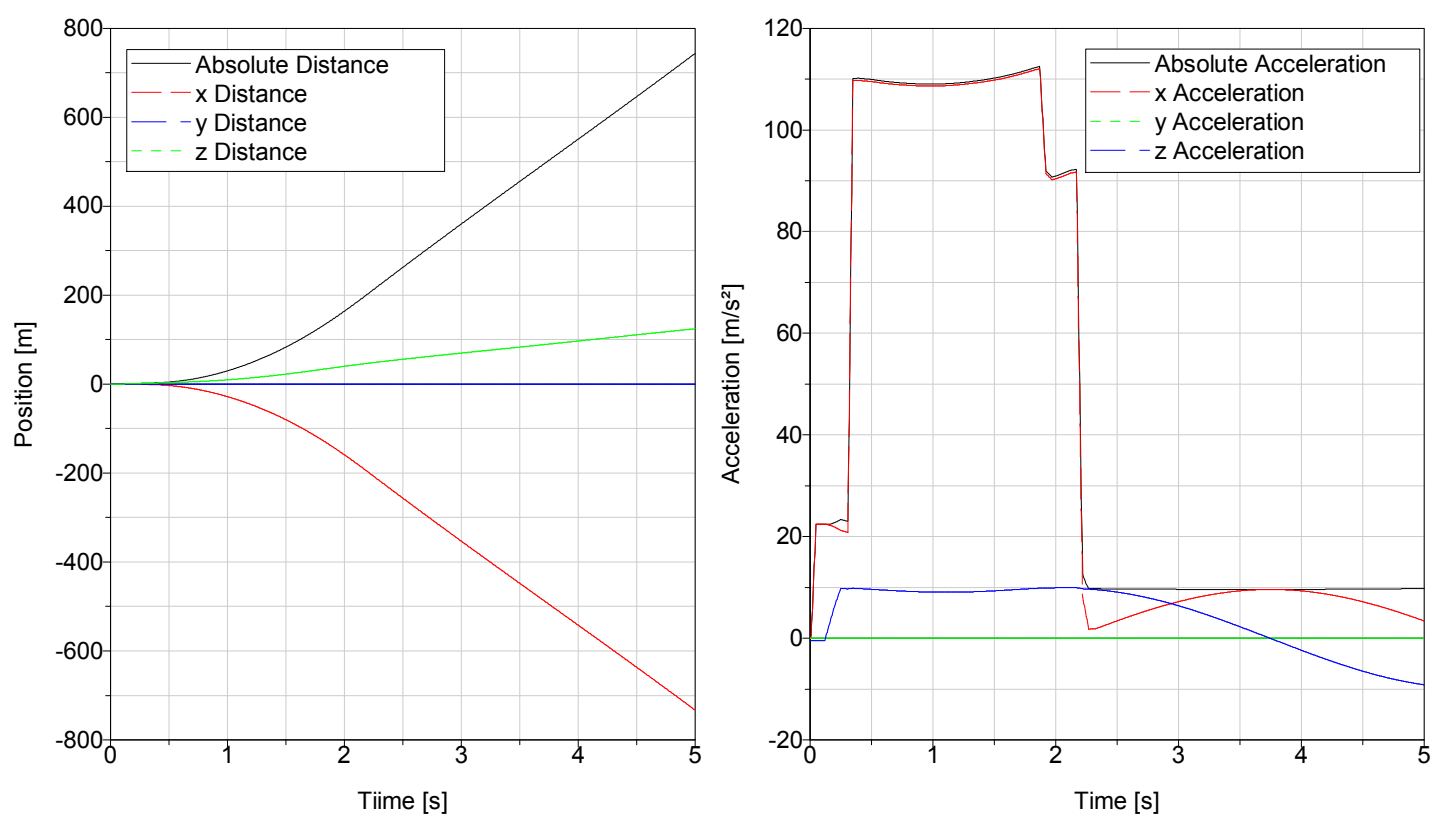

Fig. 14: Distance and accelerations of the SLC's COG in the inertia system

However, considering that passengers are seated in front of the capsule, where the upward rotation induces additional accelerations, the lateral g-forces are greater. The respective accelerations in z-axis (wrt the SLC bodyaxis) are shown in Fig. 15 with respect to point $3 \mathrm{~m}$ from the front of the nose at the same height as the CoG (named "Nose" in the diagram). A passenger seated at that point experiences a maximum lateral acceleration of $3.8 \mathrm{~g}$, thus exceeding the value of $3.5 \mathrm{~g}$ specified in the requirements. Hence, the force acting on the nose has to be reduced, but should be still able to tilt the nose upwards to the desired orientation. This, however, requires the force to act longer on the nose before the engines are ignited. Hence, the safety distance might not be reached within the specified time. This issue has to be addressed in the further development of the SLC and the ejection process.

The angular velocities shown in Fig. 15 show another issue of the SLC ejection. As expected, the force acting on the nose produces a positive moment about the y-axis. However, once all engines are ignited the angular velocity reverses and at the end of the engine burn the rotation rate is around $55 \%$. This rotational rate arises due to the fact that the total thrust vector does not point directly through the CoG. Hence, the thrust vector of the engine has to be adapted or the engines have to be repositioned. The former requires the nozzles to be tilted in- or outwards and thus decreases the thrust available for acceleration of the capsule. The latter is difficult due to the limited size of the capsule rear end. A possible solution could also be to change the SLC's CoG by changing the accommodation of the different subsystems. However, the design process of the capsule has to take the effects of different CoG positions by seating of the passenger and luggage storing and its effects on the emergency separation into consideration. 

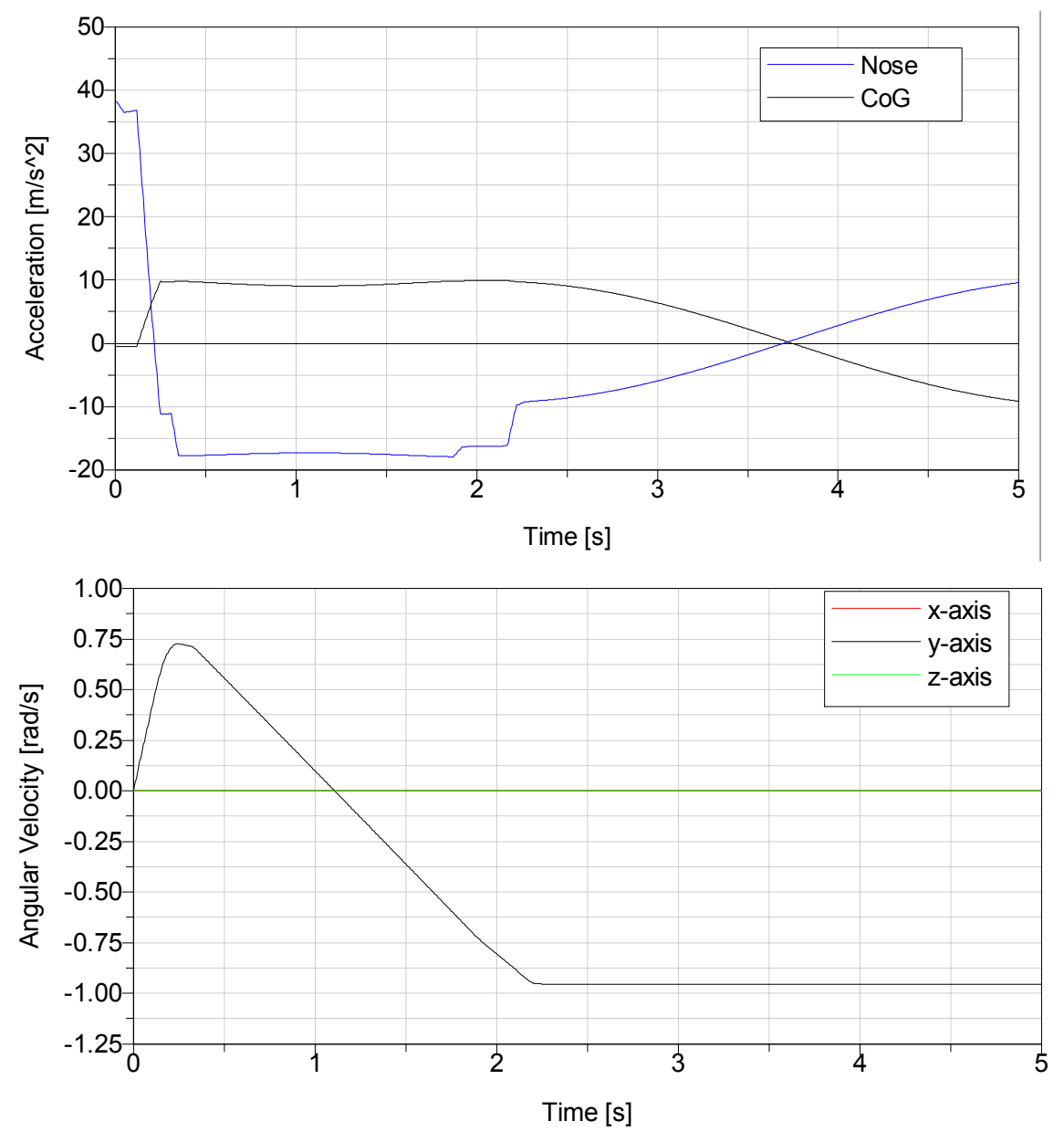

Fig. 15: Acceleration along z-axis of the SLCs CoG and the nose (top) and angular velocities (below) wrt body-fixed coordinates

The visualization of the separation procedure depicted in Fig. 16 shows that the separation process as currently modelled is not possible without collision with the SLP. It has to be noted that no reaction forces between the SLP and SLC are observed, since neither a guiding system nor any joint connections at the point of separation motor ignition are modelled in the framework. The capsule collides with the front water tank after around 0.35 seconds while also colliding with the lower part of the SLP fuselage. The capsule keeps ejecting through the front part of the nose throughout the first 0.8 seconds. Hence, this separation procedure in reality would need some sort of a guidance mechanism for the front such as the rear end of the capsule. Furthermore, the front and upper part of the SLP's fuselage would have to be ejected to minimize the risk of a collision. In future work, such a guiding mechanism as well as the jettisoning of fuselage parts will be simulated.

The results presented here are based on a preliminary simulation with simplified assumptions. The next steps are to improve the separation procedure, increase the level of simulation complexity and search for feasible solutions. Increasing the force leading to the upward rotation of the SLC at the beginning of the separation process decreases the chances of colliding with the water tank and the front parts of the SLP. However, a higher rotational rate leads to higher accelerations experienced by the passengers sitting in front which already exceed the $3.5 \mathrm{~g}$ specified in the requirements. The thrust of the SRM is also subject to optimization and might be changed. These considerations will be taken into account in the following simulations. 

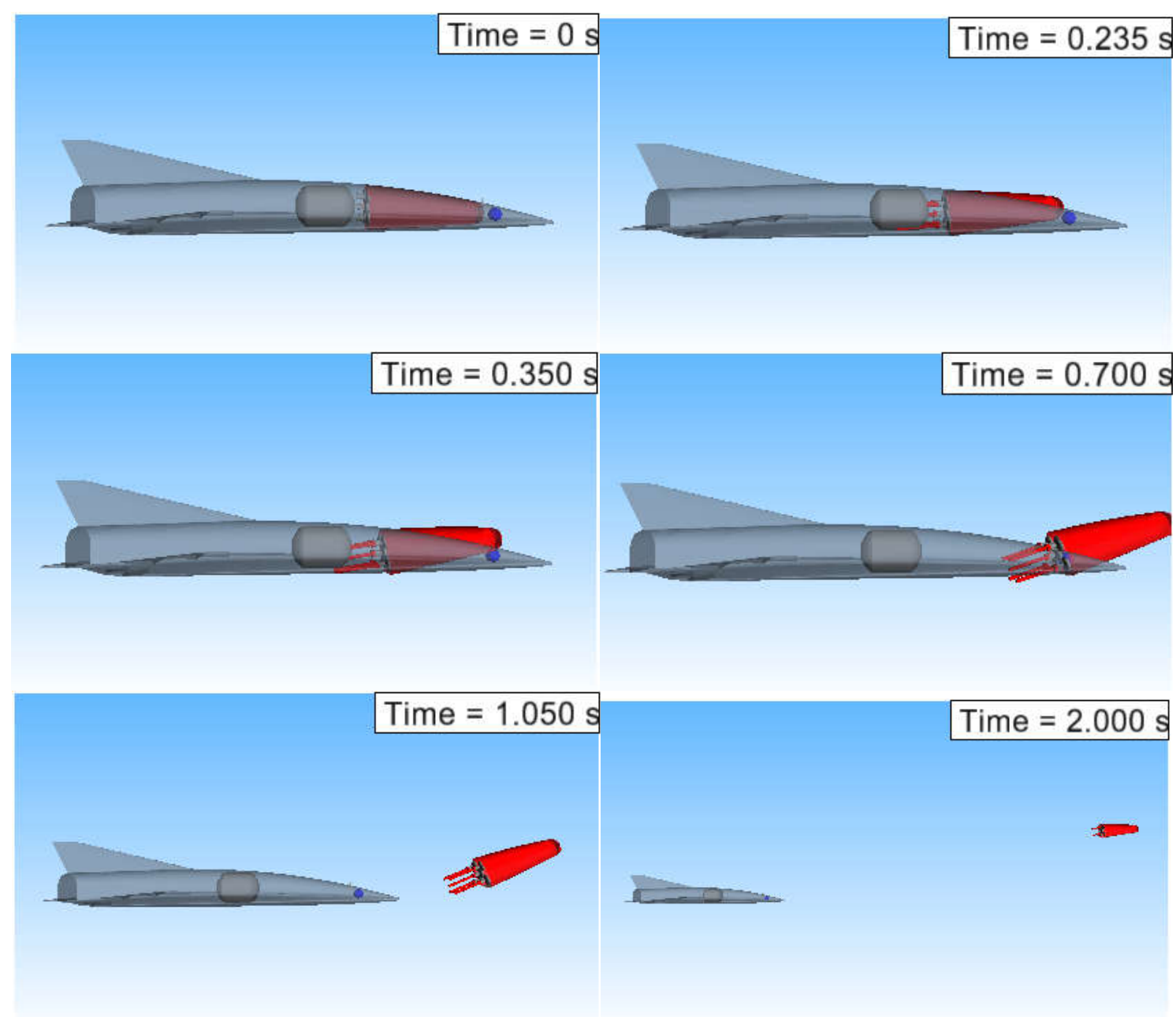

Fig. 16: Preliminary Separation procedure of the SLC

\section{Conclusion \& Outlook}

The emergency separation of the SLC from the SLP in case of a mission- and life-threatening incident during the flight is of high importance for the SpaceLiner's general safety standards. The simulation of this separation shall help in identifying critical separation phases and major problems occurring during separation that lead to the design of a feasible capsule and separation system.

Hence, MBS simulations with the Simpack tool were started that simulated an emergency separation with some simplifications. In this first simulation, collision dynamics and aerodynamics were neglected to gather a first understanding of the complexity of the separation procedure. This first simulation showed that the safety range could be achieved within the time specified but collisions between the SLC and the SLP occur. Also, further detail has to be put in the accelerations occurring in the nose part of the SLC, since the simulation showed that the load limitations are exceeded with the current separation procedure.

The cabin escape system design is a highly interdisciplinary, interdependent and iterative process. At the current point of the SpaceLiner project, the design of the cabin and the ejection system are still open to changes. In the future course of the project, a systems engineering approach shall be used to obtain a feasible and viable solution for the design of said system. This system engineering approach shall be used to derive functional abilities and constraints of the cabin system at every point of the mission to determine the dependencies of the cabin design with regards to the different boundary conditions. Thus, system requirements shall be derived that will be used to find a feasible solution fulfilling all these requirements. 
Simultaneously, the systems of the SLC will be studied in further detail. The herein presented simulation framework shall be used in the design process of the SLC to assess different capsule designs with regard to the emergency separation. Hence, the simulation framework will be improved to include aerodynamic forces, collision detection and dynamics and jettisoning of fuselage parts. With this enhanced simulation framework, all nominal design points such as some off-nominal flight conditions shall be simulated.

The design process of the capsule is a very difficult task from a technical point of view. Hence, the herein presented capsule is not a final iterated design but is subject to thorough investigation and thus changes. Alternative concepts of the capsule design will be considered in future simulation works as well to guarantee that the final capsule design fulfils all requirements and functions.

\section{Acknowledgments}

The authors would like to acknowledge the contribution of Marco Palli of the Politecnico di Milano for the design and analysis of the capsule separation motors.

\section{References}

[1] Sippel, M., Klevanski, J., Steelant, J.: Comparative Study on Options for High-Speed Intercontinental Passenger Transports: Air-Breathing- vs. Rocket-Propelled, IAC-05-D2.4.09, October 2005

[2] Sippel, M., Bussler, L., Kopp, A., Krummen, S., Valluchi, C., Wilken, J., Prévereaud, Y., Vérant, J.-L., Laroche, E., Sourgen, F., Bonetti, D.: "Advanced Simulations of Reusable Hypersonic Rocket-Powered Stages", $21^{\text {st }}$ AIAA International Space Planes and Hypersonic Systems and Technologies Conference, Xiamen, China, March 2017

[3] Sippel, M., Wilken J.: Preliminary Component Definition of Reusable Staged-Combustion Rocket Engine, Space Propulsion 2018 conference, Seville, May 2018

[4] Sippel, M.; Schwanekamp, T.; Ortelt, M.: "Staged Combustion Cycle Rocket Engine Subsystem Definition for Future Advanced Passenger Transport”, Space Propulsion 2014, Cologne, Germany, May 2014

[5] Sippel, M., Klevanski, J., van Foreest, A., Gülhan, A., Esser, B., Kuhn, M.: "The SpaceLiner Concept and its Aerothermodynamic Challenges", $I^{s t}$ ARA-Days, Arcachon July 2006

[6] Sippel, M.; Klevanski, J.: "Preliminary Definition of the Supersonic and Hypersonic Airliner Configurations in LAPCAT”, AIAA 2006-7984, $14^{\text {th }}$ Spaceplanes Conference, November 2006

[7] Krummen, S.: Investigation of flight dynamics and effects of rotational degrees of freedom on the flight performance of asymmetric space transportation systems based on the SpaceLiner 7 concept, SART TN010/2016, December 2016

[8] Schwanekamp, T.; Bauer, C.; Kopp, A.: “The Development of the SpaceLiner Concept and its Latest Progress", $4^{T H}$ CSA-IAA CONFERENCE ON ADVANCED SPACE TECHNOLOGY, Shanghai, September 2011

[9] Bauer, C.; Garbers, N., Johannsson, M.; Lentsch, A.: "INVESTIGATIONS OF THE SPACELINER PASSENGER CAPSULE AND VARIOUS ABORT SCENARIOS”, DLRK 2012, September 2012

[10] Bonetti, D. et al: "Hypersonic Morphing for a Cabin Escape System: Results of First Design Loop", $8^{\text {th }}$ European Symposium on Aerothermodynamics for Space Vehicles, Lisbon 2015

[11] Schwanekamp, T. et al.: "CONCURRENT ENGINEERING APPROACH FOR THE PRELIMINARY STUDY OF HYPERSONIC MORPHING FOR A CABIN ESCAPE SYSTEM”, IAC-14.D1.3.10, $65^{\text {th }}$ International Astronautical Congress, Toronto, 2014

[12] Bauer, C.; Kopp, A.; Schwanekamp, T.; Clark, V.; Garbers, N.: „Passenger Capsule for the SpaceLiner“, DLRK-paper, Augsburg 2014

[13] Sippel, M. et.al.: SpaceLiner Mission Requirements Document, SL-MR-SART-0001-1/2, Issue 1, Revision 1, DLR Bremen, 2016

[14] Sippel, M.: "SpaceLiner - a Visionary Concept of an Ultra Fast Passenger Transport under Investigation in FAST20XX", AIAA 2009-7439, $16^{\text {th }}$ AIAA/DLR/DGLR International Space Planes and Hypersonic Systems and Technologies Conference, Bremen 2009 
[15] Sippel, M.; Schwanekamp, T; Trivailo, O; Kopp, A; Bauer, C; Garbers, N.: "SpaceLiner Technical Progress and Mission Definition", AIAA 2015-3582, $20^{\text {th }}$ AIAA International Space Planes and Hypersonic Systems and Technologies Conference, Glasgow, July 2015

[16] van Foreest, A., Sippel, M., Klevanski, J., Gülhan, A., Esser, B.: "Technical Background and Challenges of the SpaceLiner Concept", $7^{\text {th }}$ International Symposium on Launcher Technologies, Barcelona, Spain, April 2-5, 2007

[17] Palli,M.: Study of different options for Cabin Rescue System of SpaceLiner, SART-TN-009/2018, German Aerospace Center, 2018

[18] Johannsson M.: Capsule Rescue Motors for SpaceLiner 7.1. SART TN-018/2012, German Aerospace Center, Germany, 2012

[19] Simpack GmbH: SIMPACK Documentation, Release 2015

[20] Sippel, M.: "Introducing the SpaceLiner Vision", $7^{\text {th }}$ International Symposium on Launcher Technologies, Barcelona, Spain, April 2-5, 2007

[21] van Foreest, A.; Sippel, M.: "The Logistical Challenges of the SpaceLiner Concept", IAA $1^{\text {st }}$ Symposium on Private Human Access to Space, Arcachon May 28-30 2008

[22] Sippel, M.: "Promising roadmap alternatives for the SpaceLiner", Acta Astronautica, Vol. 66, Iss. 11-12, (2010)

[23] Trivailo, O. et.al.: SpaceLiner Mission Requirements Document, SL-MR-SART-00001-1/2, Issue 1, Revision 2, SART TN-005/2016, 11.07.2016

[24] Sippel, M., van Foreest, A.: "SpaceLiner Rocket-Powered High-Speed Passenger Transportation Concept Evolving in FAST20XX", IAC-10-D2.4.06, September 2010

[25] Kopp, A.; van Foreest, A., Sippel, M.; Dalenbring, M.; Jarlas, R.: "Investigation of Structure for the Hypersonic Transport System SpaceLiner", AIAA 2011-2373, $17^{\text {th }}$ AIAA International Space Planes and Hypersonic Systems and Technologies Conference, April 2011

[26] Neeb, D., Schwanekamp, T., Gülhan, A.: "Preliminary Aerodynamic Shape Optimization of the SpaceLiner by Means of Engineering Methods", AIAA 2011-2299, $17^{\text {th }}$ AIAA International Space Planes and Hypersonic Systems and Technologies Conference, April 2011

[27] Sippel, M. van Foreest, A.; Bauer, C.; Cremaschi, F.: "System Investigations of the SpaceLiner Concept in FAST20XX, AIAA 2011-2294", $17^{\text {th }}$ AIAA International Space Planes and Hypersonic Systems and Technologies Conference, April 2011

[28] Sippel, M.; van Foreest, A.; Dietlein, I.; Schwanekamp, T.; Kopp, A.: System Analyses Driving Improved Aerothermodynamic Lay-out of the SpaceLiner Configuration, ESA-SP692, May 2011

[29] Sippel, M.; Schwanekamp, T.; Bauer, C.; Garbers, N.; van Foreest, A.; Tengzelius, U.; Lentsch, A.: “Technical Maturation of the SpaceLiner Concept", AIAA2012-5850, $18^{\text {th }}$ AIAA International Space Planes and Hypersonic Systems and Technologies Conference, Tours, September 2012

[30] Garbers, N.: "Overall Preliminary Design of the Thermal Protection System for a Long Range Hypersonic Rocket-Powered Passenger Vehicle (SpaceLiner)", ESA TPS-HS Workshop 2013

[31] Trivailo, O.; Sippel, M.; Lentsch, A.; Sekercioglu, A.: "Cost Modeling Considerations \& Challenges of the SpaceLiner - An Advanced Hypersonic", Suborbital Spaceplane, AIAA Space2013 conference, San Diego, September 2013

[32] Sippel, M.; Schwanekamp, T.; Trivailo, O.; Lentsch, A.: "Progress of SpaceLiner Rocket-Powered HighSpeed Concept", IAC-13-D2.4.05, IAC2013, Beijing, September 2013

[33] Schwanekamp, T.; Morsa, L.; Zuppardi, G.; Molina, R.: SpaceLiner 7-2 Aerodynamic Reference Database, SART TN-026/2012, 2013

[34] Schwanekamp, T.; Ludwig, C.; Sippel, M.: "Cryogenic Propellant Tank and Feedline Design Studies in the Framework of the CHATT Project", $19^{\text {th }}$ AIAA International Space Planes and Hypersonic Systems and Technologies Conference, AIAA Aviation and Aeronautics Forum and Exposition, June 2014

[35] Kopp, A.; Garbers, N.; Jarlas, R.: "Parametric Structural Analysis for the SpaceLiner", AIAA2012-5944, $18^{\text {th }}$ AIAA International Space Planes and Hypersonic Systems and Technologies Conference, Tours, September 2012 
[36] Kopp, A., Garbers, N.: "Structural and TPS Trade-Off Studies for the Hypersonic Transport System SpaceLiner", $13^{\text {th }}$ European Conference on Spacecraft Structures, Materials, and Environmental Testing, Braunschweig, Germany, April 2014

[37] Schwanekamp, T.; Bütünley, J.; Sippel, M.: "Preliminary Multidisciplinary Design Studies on an Upgraded 100 Passenger SpaceLiner Derivative", AIAA 2012-5808, $18^{\text {th }}$ AIAA International Space Planes and Hypersonic Systems and Technologies Conference, Tours, September 2012

[38] Sippel, M.; Schwanekamp, T.: "The SpaceLiner Hypersonic System - Aerothermodynamic Requirements and Design Process", $8^{\text {th }}$ European Symposium on Aerothermodynamics for Space Vehicles, Lisbon, March 2015

[39] Sippel, M., Trivailo, O., Bussler, L., Lipp, S., Kaltenhäuser, S.; Molina, R.: "Evolution of the SpaceLiner towards a Reusable TSTO-Launcher", IAC-16-D2.4.03, September 2016

[40] Laroche, E.: "Aerothermodynamics analysis of the Spaceliner Cabin Escape System modified via a morphing system", $8^{\text {th }}$ European Symposium on Aerothermodynamics for Space Vehicles, Lisbon 2015

[41] Haya, R.; Costa, H.; Bonetti, D.; Schwanekamp, T.; Gambacciani, G.; Sourgen, F.; Laroche, E.: "Hypersonic Morphing for a Cabin Escape System", IAC-14.D6.2-D2.9.2, $65^{\text {th }}$ International Astronautical Congress (IAC), Sep 29-Oct 3, 2014, Toronto, Canada

[42] Haya Ramos, R. et al: “Aerodynamics and Flying Qualities Requirements for a Long-range Transportation System", $8^{\text {th }}$ European Symposium on Aerothermodynamics for Space Vehicles, Lisbon 2015

[43] Schwanekamp, T.; Mayer, F.; Reimer, T.; Petkov, I.; Tröltzsch, A.; Siggel, M.: "System Studies on Active Thermal Protection of a Hypersonic Suborbital Passenger Transport Vehicle", AIAA Aviation Conference, AIAA 2014-2372, Atlanta, June 2014

[44] Schwanekamp,T., Garbers, N.; Sippel, M.: "Conceptual Design of the SpaceLiner Thermal Protection System", $8^{\text {th }}$ European Symposium on Aerothermodynamics for Space Vehicles, Lisbon 2015

[45] Zuppardi, G.; Morsa, L.; Sippel, M.; Schwanekamp, T.: “Aero-Thermo-Dynamic Analysis of the SpaceLiner7.1 Vehicle in High Altitude Flight", Proceedings of the $29^{\text {th }}$ International Symposium on Rarefied Gas Dynamics, 2014, AIP Conf. Proc. 1628, 1268-1276 (2014); doi: 10.1063/1.4902737

[46] Trivailo, O.: Innovative Cost Engineering Analyses and Methods Applied to SpaceLiner - an Advanced, Hypersonic, Suborbital Spaceplane Case-Study, PhD Thesis 2015

[47] Lipp, S.; Bauer, C.; Trivailo, O.: Spaceport Concepts and Locations for the SpaceLiner, SART TN-022/2014, October 2014

[48] Casali, E.; Bussler, L.; Sippel, M.: Investigation of feasible flight trajectories and re-entry atmospheric guidance for SpaceLiner 7, SART-TN014/2015, 2016 